\title{
Overcoming America's opioid epidemic will need action not words
}

Rahul Gupta, MD, MPH, MBA, FACP1

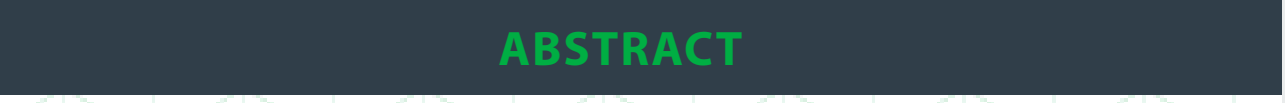

Opioids kill thousands of Americans each year. The opioid epidemic is the worst public health disaster in our nation's history. The crisis touches countless communities, is a pivotal driver of the diminishing labor force and costs the country billions of dollars each year. West Virginia has the highest death rate due to drug overdose. It is important to identify the risk factors that can lead to overdose and seek science based and practical recommendations to tackle the problem.
Author affiliations are listed at the end of this article.

Correspondence to: Rahul Gupta, MD, MPH, MBA, FACP West Virginia State Health Officer Rahul.Gupta@wv.gov

\section{KEYWORDS}

Opioids, Heroin, Fentanyl

According to the Centers for Disease Control and Prevention $(C D C)$, opioids, including prescription opioids, heroin, and fentanyl, killed more than 42,000 Americans in 2016 - the equivalent of a Boeing-737 crashing every single day. Clearly, this is the worst public health disaster our nation has faced in its 241-year history. Numbers have not yet peaked with this epidemic evolving. While the epidemic originally began as an iatrogenic crisis rooted in the dramatic over-prescription of opioids, over time, many addicted individuals have transitioned to cheaper, more readily accessible street options such as heroin and fentanyl analogues. This shift in substances is creating an entire set of challenges including the risk of significant outbreaks from diseases such as HIV and hepatitis in persons who inject drugs (PWID).

Not only has this crisis decimated almost every community in West Virginia and across the nation, the opioid epidemic has become a pivotal driver of declining labor force participation rates. New research from the White House Council of Economic Advisers finds that the cost of the crisis in 2015 was more than $\$ 500$ billion, almost 3 percent of U.S. annual economic production. In fact, Princeton economist Alan Krueger suggests that the increase in opioid prescriptions from 1999 to 2015 may account for about 20 percent of the observed decline in the male labor force participation during that same period, and 25 percent of the observed decline in the female labor force participation. Consequently, over the past 15 years, the labor force participation rate in United States fell at a higher rate in counties where more opioids were prescribed.

West Virginia continues to have the highest rates of death due to drug overdose $(52.0$ per 100,000$)$ in the nation. In 2016, that rate was 33 percent higher than the next state, Ohio (39.1 per 100,000). Additionally, West Virginia also has among the highest prevalence rates in the nation for hepatitis $B$ and $C$ indicating a considerable degree of ongoing disease transmission in PWID and shifting the cost burden of treatment onto society.

To better understand overdose deaths in West Virginia, we examined health system data for residents who died of an overdose in 2016. The 
findings are noteworthy. The majority (81\%) of overdose decedents interacted with at least one health system prior to their death. We found that 91 percent of all decedents had a documented history within the Controlled Substance Monitoring Program. In the 30 days prior to death, nearly half (49 percent) of female and 36 percent of male decedents filled a controlled substance prescription. Additionally a third of the decedents tested positive for a controlled substance, but had no record of a prescription at their time of death, indicating diversion of a controlled substance prescription. In fact, we found that decedents were three times more likely to have three or more prescribers and were more than 70 times likely to have prescriptions at four or more pharmacies compared to the overall population in the Controlled Substance Monitoring Program. While about 71 percent of all decedents utilized emergency medical services within the 12 months prior to their death, regardless of the type of EMS run, only 31 percent of decedents had naloxone administration documented in their EMS medical record. Over half ( 56 percent) of all decedents were found to be ever incarcerated and were at an increased risk of death in the 30 days after their date of release. This was the case especially in decedents with only some high school education. Additionally, it was determined that decedents were much more likely to have Medicaid (71 percent) in the 12 months prior to their death. We also found that males working in blue collar industry, or industries that come with higher risk of injury, may also be at increased risk for overdose death. These data are critical in helping us to identify risk factors that may lead to an overdose in West Virginia.

In December 2017, West Virginia's newly created Office of Drug Control Policy brought together national and regional experts from Johns Hopkins Bloomberg School of Public Health, Marshall University and West Virginia University to engage the public and develop science based and public informed practical recommendations that could be immediately put into action.

The panel issued a set of recommendations aimed at limiting the supply side by expanding the authority of professional boards to stop inappropriate prescribing of pain medications while limiting the duration of initial opioid prescriptions. It also recommends expanding awareness of substance use disorder as a treatable disease and reflecting the need for all patients to have access to multiple options for treatment. On the demand side, the panel recommends requiring a statewide quality strategy for opioid use disorder treatment (including at emergency rooms and in the correctional system) along with the removal of unnecessary regulatory barriers to the expansion of effective treatment. Considering that only when individuals survive can they have the opportunity to enter treatment and recovery, all first responders should carry naloxone and be trained in its use. Knowing we also must begin to work upstream to impact lives, the panel recommends expanding strategies such as law enforcement diversion programs to help individuals access treatment and achieve sustained recovery as well as opportunities for family planning.

Our nation is at an inflection point. We must begin to untangle the mystery of solving the crisis through an empirical, evidence-based, comprehensive approach and then support those strategies in a resourced manner. We must understand that not every well-intentioned tactic to addressing the crisis is a good idea. The arrest and imprisonment of millions of Americans for their addiction has not only complicated efforts to address the opioid epidemic, but is also a very expensive way to fail. While incarcerated, addicted individuals often lose their tolerance to opioids, increasing the chance of overdose upon reentry. Active diversion programs, drug courts, and much greater access to treatment within the corrections system and at the time of reentry into society are not only cost-effective but make common sense.

The use of opioid agonists like methadone and buprenorphine reduces overdose, illicit drug use, crime, and transmission of infectious diseases. Thus, it is critical to provide the opportunity to incorporate these effective medications into abstinence-only programs.

Although overdose deaths are merely the most visible and easily counted symptom of the problem, millions of Americans continue to suffer from addiction. While addressing the opioid epidemic will 
take a combination of solutions, it starts by taking action. Fortunately, West Virginia is well on its way towards that goal.

\section{AUTHOR AFFILIATIONS}

1. West Virginia Department of Health and Human Resources Bureau for Public Health, Charleston, West Virginia 